\title{
Structural Modeling and Modal Analysis of Hot-line Work Across the Line Construction
}

\author{
Xu Li ${ }^{1,2, a}$, Fu Yanyi ${ }^{3}$, Li Hui ${ }^{1,2}$, Xiao Lihua ${ }^{4}$, Guo Hao ${ }^{1,2}$, Liao Zhikai ${ }^{1,2}$,Li Jinliang ${ }^{1,2}$, and Yi Ziqi ${ }^{1,2}$ \\ ${ }^{1}$ State Grid Hunan Electric Power Co., Ltd. maintenance company, 410000 Changsha, China \\ ${ }^{2}$ Intelligent Hot-line Work Technology and Equipment (Robot) Key Laboratory of Hunan Province, 410000 Changsha, China \\ ${ }^{3}$ State Grid Hunan Electric Power Co., Ltd. Luxi county power supply branch, 416100 Luxi , China \\ ${ }^{4}$ State Grid Hunan Electric Power Co., Ltd., 410000 Changsha, China
}

\begin{abstract}
For the nonlinear structures such as traverse and mesh spanning structure, it is very difficult to analyze the traditional calculation method. The initial shape of the structure is determined by the finite element method and the accuracy of the model is verified. Based on this model, the natural frequencies and vibration modes of the structure are analyzed and determined, which can provide reference for transient dynamic analysis.
\end{abstract}

\section{INTRODUCTION}

In the tension erection project of transmission lines, both the conductor and the sealing structure have high flexibility and geometric nonlinearity, which belong to the cable network structure. The structure takes a series of tension ropes as the main load-bearing components and hangs on the supporting structure according to a certain geometric configuration.In order to analyze the cable-net structure more accurately, the initial configuration of the cable-net structure should be determined firstly.Because of the geometric nonlinearity of cable-net structure, it is very difficult or even impossible to calculate this kind of structure by analytic method. However, nonlinear finite element method based on discretization can solve this kind of problem very well.Based on the nonlinear finite element method and the basic principle of form finding of cable-net structure, this paper establishes the finite element model of a certain traverse and the spanning structure of the sealing net, and carries out the modal analysis of the finite element model of the traverse and the spanning structure of the sealing net, which provides a reference for the transient dynamic analysis.

\section{THE PRINCIPLE AND PROCESS OF FINDING SHAPE OF CABLE NET STRUCTURE}

The basic principle of form finding by finite element method is to create a linear model or a plane model of a cable or a network in the plane where the cable curves or its network is located, and then apply gravity load after setting a large initial strain and a small elastic modulus.At this time, the deformation of the model is the line shape of the initial state of the cable net
structure.In this linear form, the actual elastic modulus of the model is restored and the initial state of the cable-net structure under gravity load is obtained by assuming a small initial strain[1].Based on the above basic principles, this paper uses ANSYS platform to establish a finite element model for a certain traverse and the sealing network spanning structure.

\section{FINITE ELEMENT MODEL OF THE TRAVERSE AND SEALING NETWORK SPAN THE STRUCTURE}

\subsection{The finite element model of the wire}

\subsubsection{Wire parameters}

In this paper, a finite element model of the overhead wire in the construction of tension erecting a certain place is established.The spacing of the overhead rack is $369 \mathrm{~m}$, and the height difference is $-4.3 \mathrm{~m}$.In the construction, we use the tension of one line to pull four lines to cross the charged line below. The parameters of overhead conductors are shown in Table 1.

Table 1. Parameters.

\begin{tabular}{|c|c|}
\hline Wire model & LGJ-500/45 \\
\hline Sectional area $\left(\mathrm{mm}^{2}\right)$ & 531.68 \\
\hline Integrated modulus of & 65000 \\
\hline Comprehensive line & $20.5 \times 10^{-6}$ \\
\hline
\end{tabular}




\begin{tabular}{|c|c|}
\hline Unit length weight $(\mathrm{kg} / \mathrm{m})$ & 1.688 \\
\hline Self weight ratio load $(\mathrm{MPa} / \mathrm{m})$ & $31.135 \times 10^{-3}$ \\
\hline $\begin{array}{c}\text { Horizontal actinomycete } \\
\text { tension(N) }\end{array}$ & 26000 \\
\hline
\end{tabular}

\subsubsection{Selection of unit type}

Wire is a structure with great slenderness ratio, and can not withstand axial pressure and bending moment, can only withstand axial tension, so link 10 unit is chosen to simulate the wire[2].The geometric node position and coordinate system of the link10 unit is shown in Figure 1.

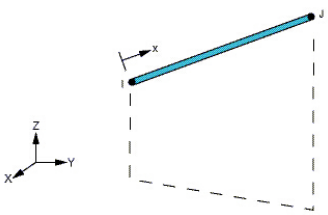

Figure 1. link10 element model.

The element is defined by two nodes, cross section, initial stress or gap, and various properties of the same material.The unit $\mathrm{X}$ axis is the direction of the unit length along the node I to node J.Each node has three degrees of freedom of translation in the direction of X, Y, and Z.The KEYOPT (3) attribute of the unit is set to 0 when the wire is simulated, which is only the option of pulling force(Cable).And a positive initial strain value is set to indicate that it is in a tensioned state.

\subsubsection{Setting of boundary conditions}

The overhead conductor is suspended at the suspension points on the left and right sides to maintain a certain sag under the combined action of gravity and horizontal tension. Therefore, the boundary condition is that the degree of freedom at the suspension point is 0 , and the points of the traverse are subjected to gravity. The bottom line tension of the lowest point of the wire is $\mathrm{H}_{0}=$ $104000 \mathrm{~N}$.

\subsubsection{Shape finding analysis}

The finite element model of the traverse after form finding analysis is shown in Figure 2.

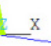

Figure 2. Wire element model after wire form finding.

As can be seen from Figure 2.2, the traverse is analyzed by form finding after a straight line model between two suspension points, which becomes a catenary model with a certain sag.

\subsubsection{Verification of results of form finding analysis}

After the shape analysis of the conductor, the accuracy of the model needs to be checked.Comparing the relative errors between the $\mathrm{Y}$ coordinate values of a certain point on the finite element model of traverse and the $\mathrm{Y}$ coordinate values calculated by the suspension theoretical formula under uniform load, when the error is within $5 \%$, it is considered that the model established by the form finding method is accurate[3,4].

The theoretical calculation of the suspension structure under uniform load is to establish the force balance equation by selecting an arbitrary element in the cable structure.Figure 3. shows the establishment of a coordinate system for overhead conductors, with the left suspension point as the coordinate origin[5].

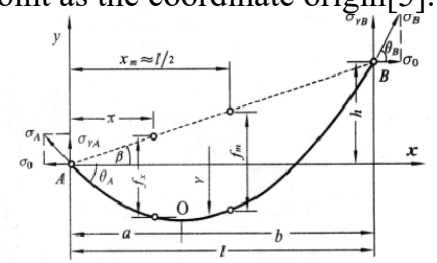

Figure 3. Cable structure catenary under uniform load.

The resulting equation is formula (1).

$$
\begin{gathered}
y=\frac{2 \sigma_{0}}{\gamma} \operatorname{sh} \frac{\gamma x}{2 \sigma_{0}}\left[\frac{h}{L_{h=0}} \operatorname{ch} \frac{\gamma(l-x)}{2 \sigma_{0}}\right. \\
\left.-\sqrt{1+\left(\frac{h}{L_{h=0}}\right)^{2}} \operatorname{sh} \frac{\gamma(l-x)}{2 \sigma_{0}}\right]
\end{gathered}
$$

For the traverse described in this paper, the values of two $\mathrm{Y}$ coordinates obtained at $41 \mathrm{~m}$ intervals in the $\mathrm{X}$ coordinate direction are listed in Table 2.

Table 2. Sag coordinates of overhead lines under self weight action.

\begin{tabular}{|c|c|c|c|c|}
\hline No. & $\begin{array}{c}\text { Theoretic } \\
\text { al value }\end{array}$ & $\begin{array}{c}\text { Analog } \\
\text { value }\end{array}$ & $\begin{array}{c}\text { Absolu } \\
\text { te error }\end{array}$ & $\begin{array}{c}\text { Relative } \\
\text { error(\%) }\end{array}$ \\
\hline 1 & -4.759 & -4.768 & 0.009 & -0.19 \\
\hline 2 & -8.447 & -8.461 & 0.014 & -0.17 \\
\hline 3 & -11.066 & -11.08 & 0.014 & -0.13 \\
\hline 4 & -12.614 & -12.627 & 0.013 & -0.10 \\
\hline 5 & -13.092 & -13.104 & 0.012 & -0.09 \\
\hline 6 & -12.499 & -12.51 & 0.011 & -0.09 \\
\hline 7 & -10.836 & -10.846 & 0.01 & -0.09 \\
\hline 8 & -8.103 & -8.11 & 0.007 & -0.09 \\
\hline
\end{tabular}

From Table 2, we can see that the relative error between the simulated value of $\mathrm{Y}$ coordinate and the calculated value is far less than $5 \%$, which indicates that the model is accurate.

\subsection{Finite element model of closed network spanning structure}

The closed network spanning structure includes loading cable and sealing device.The two ends of the loadbearing cable are suspended on temporary crossbars on both sides of the tower, and the load-bearing cable and the sealing device are connected by hooks or pulleys, which form protection for the tracted conductors in construction.

\subsubsection{Closed network spanning structural parameters}


In this paper, a closed network spanning structure in live span construction is taken as an example, and its finite element model is established.Span $1=369 \mathrm{~m}$, height difference $\mathrm{h}=-4.3 \mathrm{~m}$. The lowest stress of the bearing cable is $40.517 \mathrm{mpa}$. The parameters are shown in Table 3.

Table 3. Parameters.

\begin{tabular}{|c|c|c|c|c|c|}
\hline No. & Name & $\begin{array}{c}\text { Specific } \\
\text { ations }\end{array}$ & $\underset{\text { er }}{\text { Numb }}$ & $\begin{array}{l}\text { Calculate } \\
\text { d weight }\end{array}$ & purpose \\
\hline 1 & Dyneema & $\Phi 16$ & $\begin{array}{l}400 \mathrm{~m} \times \\
2\end{array}$ & $\underset{\mathrm{m}}{0.195 \mathrm{~kg} /}$ & $\begin{array}{l}\text { Load-bearing } \\
\text { cable }\end{array}$ \\
\hline 3 & $\begin{array}{l}\text { High strength } \\
\text { nylon rope net }\end{array}$ & $\Phi 12$ & 7 & $8.5 \mathrm{~kg} /$ one & Close network \\
\hline 4 & $\begin{array}{l}\text { Strut of } \\
\text { insulated } \\
\text { network }\end{array}$ & $\Phi 50 \times 8$ & 8 & $8 \mathrm{~kg} / \mathrm{one}$ & Bracing network \\
\hline 5 & $\begin{array}{l}\text { Pulley for stay } \\
\text { bar }\end{array}$ & $1 \mathrm{t}$ & 16 & $\begin{array}{c}0.45 \mathrm{~kg} / \mathrm{on} \\
\mathrm{e}\end{array}$ & Bearing rod \\
\hline 6 & $\begin{array}{l}\text { Connection } \\
\text { hook }\end{array}$ & $1 \mathrm{t}$ & 56 & $\begin{array}{c}0.45 \mathrm{~kg} / \mathrm{on} \\
\mathrm{e}\end{array}$ & $\begin{array}{l}\text { Connection } \\
\text { network }\end{array}$ \\
\hline
\end{tabular}

\subsubsection{Unit type selection}

Both the load-bearing cable and the insulation network are flexible structures, which are consistent with the mechanical properties of the conductors. So the loadbearing cable and the insulation network are still simulated by link10 [6] element.The MASS21 element is used to simulate the pulley and the hook, because only the influence of its weight on the overall structure needs to be considered.The braces need to withstand tension, pressure and bending moment, so the beam 4 beam element is used to simulate.[7]The cell model of the beam 4 cell is shown in Figure 4.

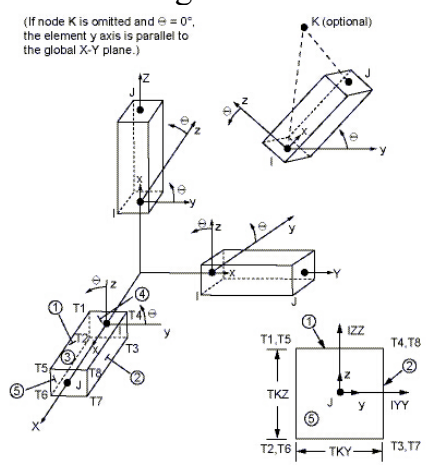

Figure 4. Beam4 cell model.

As shown in Figure 2.4, the cross-section of beam 4 element is rectangular, and its cross-section shape is defined by the values TKZ and TKY.Because the supporting rod cross section is circular, the two section should be treated equally. The equivalent principle of rectangle and circular section is that the two cross sections are equal to the moment of inertia of $Y$ axis and $\mathrm{Z}$ axis. The formula for calculating the moment of inertia of rectangular section is[8]:

$$
\begin{aligned}
& \text { Y axis: } I_{\mathrm{y}}=(T K Y)(T K Z)^{3} / 12 \\
& Z \text { axis: } I_{\mathrm{z}}=(T K Z)(T K Y)^{3} / 12
\end{aligned}
$$

The formula for calculating the two axis moment of inertia of a circular section is:

$$
I_{\mathrm{y}}=I_{\mathrm{z}}=\pi R^{4} / 64
$$

The definition of beam 4 unit section is square, and the support diameter is $50 \mathrm{~mm}$, so $T K Y=T K Z=21.902 \mathrm{~mm}$.

\subsubsection{Setting of boundary conditions}

Because the closed net spanning structure is hanging on $t$ he temporary cross-bearing of the towers on both sides, $i$ $t$ keeps a certain sag under the combined action of gravit $y$ and horizontal tension. Therefore, the boundary conditi on is that the degree of freedom of the suspension point $i$ s 0. All parts of the spanning structure of a closed networ $\mathrm{k}$ are subjected to gravity. The horizontal tension of a sin gle bearing cable is $40.517 \mathrm{MPa} \times 156.701 \mathrm{~mm} 2=6349 \mathrm{~N}$.

\subsubsection{Shape finding analysis}

The same as the traverse shape finding method, the result is shown in Figure 5, and its partial enlargement is show $\mathrm{n}$ in Figure 6.

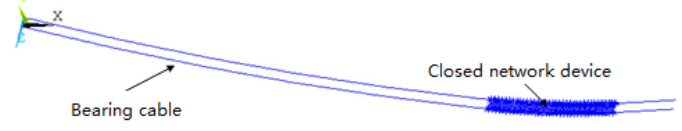

Figure 5. The finite element model of the closed structure after crossing structure.

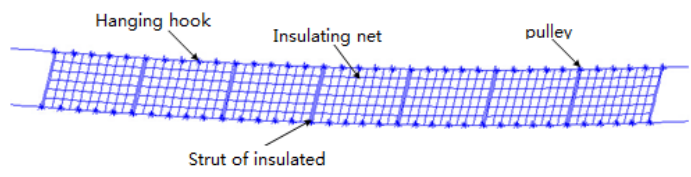

Figure 6. Closed network spanning structure finite element model partial enlargement map.

\subsubsection{Verification of results of form finding analysis}

The accuracy verification method is the same as that of traverse after form finding.However, the load-bearing cable is subjected to non-uniform load because of the effect of insulating net, insulating net strut and other components on the load-bearing cable.The theoretical formula is shown below.[5]The structure of the cable under uneven load is shown in Figure 7. 


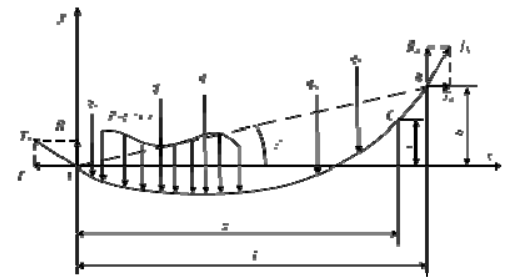

Figure 7. Structural stress diagram of cables subjected to uneven load.

The hanging curve equation under uneven load is:

$$
\begin{aligned}
y & =x \tan \beta+\frac{1}{T_{0}}\left(\sum M_{\mathrm{C}}-\frac{\sum M_{B}}{l} x\right) \\
& =x \tan \beta-\frac{M_{x}}{T_{0}}
\end{aligned}
$$

Among them, $\sum M_{\mathrm{C}}-\mathrm{C}$ point the torque of all loads on the left side of the $\mathrm{C}$ point;

$M_{\mathrm{x}}$ The bending moment of the cross section of $\mathrm{C}$ point on a simply supported beam, $M_{x}=Q_{A} x-\sum M_{\mathrm{C}}$.

For the load-bearing cables described in this paper, the values of two y-coordinates obtained at intervals of $41 \mathrm{~m}$ in the $\mathrm{x}$-coordinate direction are also listed in Table 4.

Table 4. Sag coordinates of loaded cables under self weight.

\begin{tabular}{|c|c|c|c|c|}
\hline No. & $\begin{array}{c}\text { theoretica } \\
\text { I value }\end{array}$ & $\begin{array}{c}\text { Analog } \\
\text { value }\end{array}$ & $\begin{array}{c}\text { absolut } \\
\text { e error }\end{array}$ & $\begin{array}{c}\text { relative } \\
\text { error(\%) }\end{array}$ \\
\hline 1 & -4.030 & -4.036 & 0.006 & -0.15 \\
\hline 2 & -7.555 & -7.564 & 0.009 & -0.12 \\
\hline 3 & -10.573 & -10.586 & 0.013 & -0.12 \\
\hline 4 & -13.085 & -13.099 & 0.014 & -0.11 \\
\hline 5 & -15.091 & -15.107 & 0.016 & -0.11 \\
\hline 6 & -16.590 & -16.606 & 0.016 & -0.10 \\
\hline 7 & -16.545 & -16.56 & 0.015 & -0.09 \\
\hline 8 & -11.919 & -11.93 & 0.011 & -0.09 \\
\hline
\end{tabular}

From Table 4, the relative error is far less than $5 \%$. The results show that the established finite element model is accurate.

\section{MODAL ANALYSIS OF CROSSING STRUCTURE BETWEEN TRAVERSE AND CLOSED NETWORK}

Modal analysis is used to determine the natural frequencies and modes of structures[9]. The result is the basis of other dynamic analysis such as transient dynamics.

\subsection{Modal analysis of conductors}

Modal analysis of the above traverse model is carried out.The vibration modes and frequencies of the first six orders which have great influence on the structure are shown in Figure 8.

a . First stage vibration mode $(\mathrm{F}=0.48649 \mathrm{~Hz})$ b. Second stage vibration mode $(\mathrm{F}=0.54573 \mathrm{~Hz})$

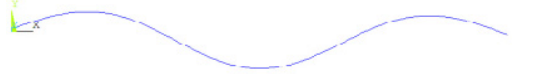

c. Third stage vibration $\operatorname{mode}(\mathrm{F}=0.83587 \mathrm{~Hz})$

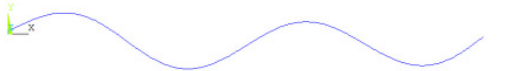

d. Fourth stage vibration $\operatorname{mode}(\mathrm{F}=1.0944 \mathrm{~Hz})$

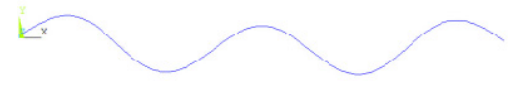

e. Fifth stage vibration $\operatorname{mode}(\mathrm{F}=1.3714 \mathrm{~Hz})$

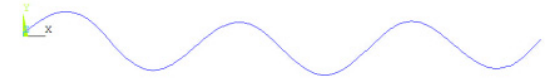

f. Sixth stage vibration $\operatorname{mode}(F=1.6426 \mathrm{~Hz})$

Figure 8. The first six stages of the traverse pattern.

From Fig. 8, it is known that the first six order vibration frequency of the conductor increases gradually, and it is low frequency vibration.Low frequency vibration should be suppressed in dynamic analysis of conductors to reduce the influence of unreal vibration on the analysis results.

\subsection{Modal analysis of closed network spanning structure}

Modal analysis is carried out for the above models of closed network spanning structure. The first six modes and frequencies of the structure which have great influence on the structure are shown in Figure 9.

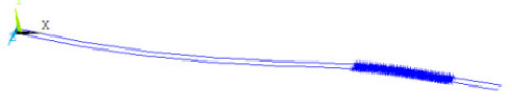

a. First stage vibration $\operatorname{mode}(\mathrm{F}=0.39137 \mathrm{~Hz})$

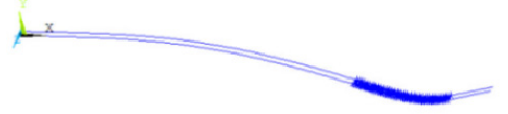

b. Second stage vibration $\operatorname{mode}(\mathrm{F}=0.49859 \mathrm{~Hz})$

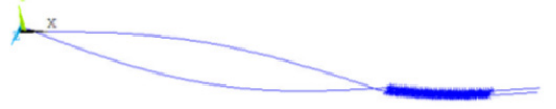

c. Third stage vibration $\operatorname{mode}(\mathrm{F}=0.57366 \mathrm{~Hz})$

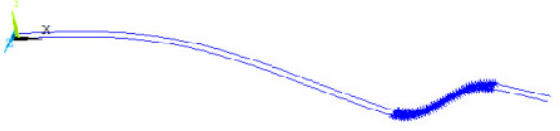

d. Fourth stage vibration $\operatorname{mode}(\mathrm{F}=0.67375 \mathrm{~Hz})$ 


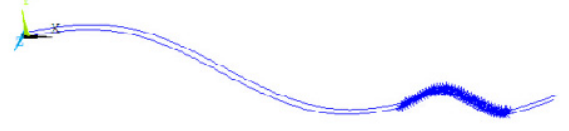

e. Fifth stage vibration mode $(\mathrm{F}=1.0086 \mathrm{~Hz})$

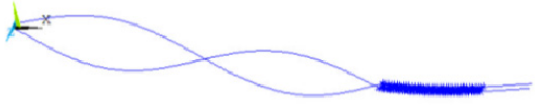

f. Sixth stage vibration mode $(F=1.0672 \mathrm{~Hz})$

Figure 9. Vibration pattern of the first six stages of the installation.

As shown in Fig. 9, the vibration frequency of the structure increases with the increase of the order of vibration. The vibration frequency of the first six orders is small, and the vibration of the device belongs to low frequency vibration. The low frequency vibration should be suppressed when analyzing the dynamics of the closed network structure to reduce the effect of non real oscillations on the analysis results.

\section{CONCLUSIONS}

(1)The traverse and enclosed network spanning structure established by the finite element method is accurate, and it provides reliable model basis for subsequent analysis of traverse and enclosed network spanning structure.

(2)The modal analysis results of conductor and enclosed network spanning structures show that both belong to low frequency vibration and lay a foundation for the subsequent transient dynamic analysis.

\section{Acknowledgment}

Project Supported by state grid hunan electric power co mpany limted science and technology project(5216AD17 001)

\section{REFERENCES}

1. Wang Xinmin.Numerical analysis of ANSYS engineering structure.Beijing:China Communications Press,467-477(2007).

2. ANSYS Chinese help manual. http://download.csdn.net/download/crysun/1307102. html,(2009).

3. Meng Suimin,Dan Luping.Research on form finding in transmission line dynamics analysis.Power grid and clean energy, 10,50-54.(2009).

4. Dan Luping.Ice skipping analysis of transmission lines.Yibin:China Three Gorges Universit, (2010).

5. Meng Suimin,Kong Wei.Overhead transmission line design.Beijing:China Electric Power Press,6063(2009).
6. Cao QiangWang Jingchun.Simulation of flexible network based on nonlinear finite element method.Journal of systems simulation,5,12701273(2009).

7. Wang Zepeng,Hu Renxi,Kang Shiting.ANSYS 13.0 / LS-DYNAA guide to nonlinear finite element analysis:A guide to nonlinear finite element analysis.Beijing:Machinery Industry Press,130131(2011)

8. Liu Hongwen.Mechanics of materials (Fourth Edition).Beijing:Higher Education Press,376379(2004).

9. $\mathrm{Xu}$ Benwen, Jiao Qunying.Foundation of mechanical vibration and modal analysis.Beijing:Machinery Industry Press, 46(1998). 